\title{
REPORTS
}

\section{PROFESSIONAL TRAINING DURING RETRENCHMENT: GOVERNMENT AND UNIVERSITY COLLABORATION WITH PUBLIC PSYCHIATRIC HOSPITALS}

\author{
Diane Vinokur-Kaplan, Ph.D., M.S.W., and Gaynell Walker- \\ Burt, Ph.D.
}

As public mental health systems continue to move from hospital-based to communitybased services, many administrators of public psychiatric hospitals are concerned with maintaining competent professional staff during such turbulent times. For example, during the past four years in Michigan, such hospital administrators have been challenged

Diane Vinokur-Kaplan is Assistant Professor at the School of Social Work, University of Michigan. Gaynell Walker-Burt was formerly Director of Quality Improvement, Michigan Dept. of Mental Health, and was Project Director of the NIMH/MDMH Demonstration Project; she is currently with the Georgia Regional Hospital in Decatur, GA. Address for correspondence: Diane Vinokur-Kaplan, School of Social Work, The University of Michigan, 1065 Frieze Bldg., Ann Arbor, MI 48109-1285.

This research was sponsored by the National Institute of Mental Health State Manpower Development Grant [\#STC (16) T23 MH19240] awarded to the Michigan Department of Mental Health, Gaynell Walker-Burt, Ph.D., principal investigator. The authors thank the directors and staff of the psychiatric hospitals who participated in the study, and the Project Advisory Committee members, and the Michigan Department of Mental Health Staff for their contributions. with austere state budgets and a continuing policy to close and consolidate state-operated facilities. During this time of change, staff in public hospitals have had to treat a more complex patient population, including increasing rates of individuals presenting with dual diagnoses of mental illness and substance abuse, and a growing proportion of patients with concurrent needs for geriatric care. In addition, hospital staff must seck more culturally-sensitive treatment for their patients who represent the diverse racial and ethnic populations of the state. Moreover, staff have been charged to implement new procedures to help guarantee continued hospital accreditation and obtain certification of facilities for reimbursement purposes. Thus, already-pressured staff have required additional training.

These various stresses have resulted in several outcomes regarding professional personnel. Some have left or retired from the state system altogether. As hospitals closed, some longer-term employees took advantage of the state-wide system of seniority rights and transferred to positions at other state hospitals or agencies slated to remain open; they thereby maintained their state positions 
and pension rights, albeit possibly by displacing less senior employees.

Given such turnover in personnel, hospital administrators are faced with several important questions: How can they provide quality mental health services, assure that professional personnel are competent and productive? How can they maintain the morale of their employees in order to diminish burnout and turnover under these changing conditions?

To help address these issues, a collaborative academic-linkage project was developed between the Michigan Department of Mental Health (MDMH) and professional schools at several state universities to address appropriate human resource strategies. This approach to strengthen human resources has been widely utilized and supported in mental health practice (Davis \& Sanchez, 1987; Talbott \& Rabinowitz, 1986). In 1989, MDMH received a grant from the National Institute of Mental Health's Center for State Human Resource Development which provided three years of funding for this partnership.

Specifically, this project sought to use three human resource development strategies-in-service training, technical assistance, and state-university collaboration - to assist state hospitals to improve the quality of their mental health services. This goal was sought, in turn, by using the resources of the universities and MDMH's central office to enhance various dimensions of the effective performance of interdisciplinary clinical treatment teams. Following is a report of the project's first phase. It describes the collaborative model and the initial results of the assessment of staff training needs and how they have been used.

\section{DEVELOPMENT OF STATEI UNIVERSITY/FEDERAL COLLABORATION}

\section{Initial Partnership}

Human resource staff at the Michigan Department of Mental Health conducted exten sive outreach to faculty in mental health disciplines at several state universities to incorporate the most recent expertise in the systematic diagnosis and the active, culturally sensitive, and interdisciplinary treatment of patients. Together, MDMH and selected faculty collaborated in developing grant proposals to establish a model demonstration project.

Such a partnership was facilitated by previous collaborative efforts between MDMH and the universities. For example, some of the faculty had been involved in the development and administration of a state-funded stipend-loan program that provided financial assistance to students in mental health disciplines who agreed to work in the public mental health system upon graduation. This program had mutually benefited the universities - by providing additional financial resources for students - and the department-by providing new, highly-trained clinical professionals.

This demonstration program effort has since been guided by an interdisciplinary, inter-university advisory board of faculty from psychiatry, nursing, social work, psychology, and occupational therapy at various professional schools and departments from four state universities (Eastern Michigan, Michigan State, University of Michigan, and Western Michigan), and professional staff from the Department, (including the medical director). Administrators from two regional public psychiatric hospitals agreed that their hospitals could serve as pilot sites. This group has continued to meet and guide this project during a time of economic uncertainties, and new mental health appointments and policies following a change in governor in the 1990 state election.

\section{Implementation of the Collaborative Project}

The two hospitals that had agreed to be pilot sites for the training program (herein referred to as Hospitals A and B) concurred that there would be a series of six in-service training sessions for staff. The first two ses- 
sions would focus on "project priorities," such as the use of standardized instruments for diagnosis, and the enhancement of team effectiveness in treatment planning. Subsequent training sessions would focus on the priority areas cited as being important by the staff members. Thus, during the first phase of the project, a training needs assessment was administered to staff to obtain their choices for subsequent training. Hospital staff were motivated to complete the assessment so that their training priorities could be considered.

The hospitals that participated were typical of those serving most areas of the state. Each hospital served approximately 250-300 adults with mental illness and is accredited by the Joint Commission on Accreditation of Health Care Organizations.

Both hospitals had been experiencing major changes in their personnel due to budget constraints, early retirements, decreased patient census, and internal and state-wide "bumping" under the seniority preference employment system. Moreover, the continuing policy of community placement and consolidation of hospital services, reinforced in the proposed programs of the new governor elected in November, 1990, provoked many rumors of additional institutions being closed and downsized, and additional employees being laid off. Furthermore, this time period coincided with various statewide efforts to obtain third-party reimbursement from Medicare and other insurers, requiring staff to incorporate changes in their treatment planning and record-keeping.

Four wards at each of the two hospitals were selected to participate; two were admission wards, and two served long-term care patients. All wards had one or two interdisciplinary teams, including professionals (activity therapists, nurses, psychiatrists, psychologists, social workers) and para-professionals (e.g., resident care attendants and licensed practical nurses). This report includes data from professionals on 11 clinical treatment teams: the two teams from each of the two admission wards in Hospital A; the two teams from long-term care units at Hos- pital A; pre-test data from a team on another admissions unit not participating in the project at Hospital A; and the teams from each of the four selected wards of Hospital B.

\section{METHOD}

\section{Training Needs Assessment Instrument}

The training needs assessment was included in a questionnaire on clinical treatment team effectiveness. It was developed using current mental health services literature and valuable input from the hospital directors, advisory board and project staff. It contains 33 items focusing on current knowledge, skills, team-building, and use of new technologies (e.g., computers). The format allowed for respondents to add additional topics of their interest. Respondents reviewed all listed areas of training and checked those items on which they wished they had training available.

\section{Procedure and Response Rates}

Questionnaires were distributed to all staff on the selected wards at the two hospitals in December, 1990. The response rate for the 77 professionals was high, with $90 \%(\mathrm{n}=69)$ returning their questionnaires. The rates varied between the two hospitals: $82 \%$ of professionals in selected wards at Hospital $A$, at which the rumors for closure were strongest, and $97 \%$ at Hospital B. The response rates of the disciplines were: psychiatrists and psychologists-100\%; social workers $-92 \%$; nurses $-88 \%$; and occupational therapists $-75 \%$.

\section{RESULTS OF TRAINING NEEDS ASSESSMENT}

The training most widely sought by these professionals focused on various aspects of team-building. The most salient was "aid in communicating their team's needs to the administration of the hospital" (chosen by $68 \%$ of the respondents). Other related topics in- 
cluded: "having more productive meetings" $(48 \%)$, "improving the morale of the team" $(46 \%)$, and "reaching decisions more quickly" $(45 \%)$.

This preference is understandable in light of the continued emphasis for teams to incorporate active treatment procedures (e.g., planning, implementing, and evaluating treatment), along with the many pressures and uncertainties surrounding the short- and longterm futures of their institutions. (Indeed, one of the hospitals was scheduled for permanent closure several weeks after the collection of these data!)

There were also three other additional areas of training sought frequently by these professionals (i.e., chosen by more than $40 \%$ ). Firstly, many had a strong desire for training "to use computers to keep and produce patients' records" (62\%). Given the extensive record-keeping and reporting that is required for hospital records and insurance reimbursement, and the many technological advances that have been made to expedite this process, it is also not surprising that such training was desired. (However, necessary equipment was not available at either hospital).

Secondly, the continued trend for de-institutionalization was reflected in these professionals' desire for more training regarding "current resources in the surrounding community for patients discharged from this hospital" $(52 \%)$. Thirdly, there was a strong desire to gain skills in "assessing substance abuse (e.g., abuse of alcohol, drugs, etc.) among patients" (42\%). This preference may reflect the high incidence of a dual diagnosis of mental illness/ substance abuse among patients, and the evergrowing pharmacopoeia to which patients may be exposed prior to admission to the hospital. Both conditions were frequently encountered by these professionals, and their prior training may not have adequately prepared them for contemporary patients' needs.

\section{Differences Between Hospitals}

There was general agreement among the various professionals in the two hospitals regarding their preferences for training topics.
However, among the respondents' top 10 ranked areas of training, there were two in which Hospital B consistently displayed a statistically significant higher proportion of professionals seeking such training, (using chi-square analysis): "Improving the morale of the team" (A's $35 \%$ vs. B's $56 \%$, p <.10), and “ . . . Substance abuse" (A's $17 \%$ vs. B's $61 \%, \mathrm{p}<.01$ ); similarly, professionals at Hospital A were significantly more interested in team-building training that promoted "Having everyone participate" (A's $45 \%$ vs. B's $19 \%, \mathrm{p}<.05$ ).

\section{Differences Among Disciplines}

Next, the three most frequently chosen training items of each professional group (nurses, occupational/recreational therapists, physicians, psychologists, and social workers) were determined, and it was found that they were chosen from among only six different items: "Communicating the team's needs to hospital administration," "Using a computer to keep and produce patient records," "Knowledge of community resources for discharged patients," "Having more productive meetings," "Reaching decisions more quickly" and "Improving morale of the team." Thus, there was considerable consensus among the disciplines regarding the training they most wanted, namely, enhancing the professionals' teamwork, productivity and work environment, and better knowledge of community-based care resources.

However, if the array of priorities is extended to include the five training items most frequently chosen by each discipline, some patterns emerge more clearly with some interesting implications for training. (A fifthranked item represents interest in training by at least $33 \%$ of one profession). Therein, there are several examples in which a particular training item is either very popular or very unpopular among all but one of the five disciplines, even though such professionals' work assignments usually include major tasks related to the training item.

For instance, the item on developing discharge planning knowledge, "[obtaining 
training on] resources in the surrounding community for patients discharged from this hospital," was chosen as a priority training item by the majority of nurses $(73 \%$, ranked $1 \mathrm{st}$ ), occupational therapists (56\%, ranked 8 th), physicians (78\%, ranked first), psychologists $(50 \%$, ranked third) - and none of the social workers $(0 \%$, tied ranking for last, (chi-square, p < .001))! Similarly, none of the physicians were interested in training on "the use and various effects of medications used in treating mental illness," yet more than a quarter of the other professions expressed such interest: nurses - 27\% (ranked 23rd); occupational therapists - 44\% (ranked 12th); psychologists - 33\% (ranked 5th); and social workers - 39\% (ranked 9th), (chisquare, $\mathrm{p}<.10$ ).

Conversely, training on acquiring skills for "assessing the social functioning of a patient" was highly ranked and sought by a substantial proportion of the physicians (44\%, ranked 4th), but comparatively much less highly ranked by the other professions: nurses $(45 \%$, ranked 12 th), occupation therapists $(44 \%$, ranked 14 th), psychologists ( $8 \%$, ranked 26 th); and social workers $(2 \%$, ranked 30th), (chi-square, $\mathrm{p}<.07$ ). Similarly, a high proportion of the occupational therapists expressed interest in training on "determining appropriate criteria for discharging patients" (67\%, ranked 4th), but less than a third of each other discipline did so: nurses (27\%, ranked 24th); physicians (11\%, ranked 23rd); psychologists $(25 \%$, ranked 15th); and social workers (23\%, ranked 15 th) (chi-square, $p<.10$ ). Likewise, the majority of nurses were interested in training on "Revising and updating a treatment plan" (59\%, ranked 4th), whereas much less interest was indicated by the other professions: occupational therapists - $22 \%$, (ranked 25th); physicians - 11\%, (ranked 16 th); psychologists - 0\%, (tied for last); and social workers - 3\%, (ranked 29th), (chisquare, $\mathrm{p}<.01$ ).

Such findings have at least two implications for training. Firstly, some priority training needs are discipline-specific, and may not be equally sought or needed by professionals in a particular mental health setting; therefore, training must be appropriately tailored for various disciplines. Secondly, some staff may have already developed particular expertise in specific areas that are needed by staff from other disciplines. Tapping those employees who demonstrate expertise in areas of training needed by other employees generates an excellent way to recognize and reward them. Thus, administrators should consider using inhouse professionals to provide relevant training to teams and disciplines within the institution, rather than recruiting more expensive "experts from outside," especially in this period of tight training budgets.

For example, a particularly well-informed social worker could be assigned as the hospital's own "community resources specialist" and provide training to other teams or other disciplines in the hospital. Indeed, continuing consultation with the "specialist" in an area might be more available and more accessible to other hospital professionals given his/her "in-house" status.

\section{CONCLUSIONS}

As mental health administrators seek ways to enhance the skills and morale of their professionals during times of retrenchment, they might consider the strengths of this particular collaborative model. It invokes the expertise of university faculty with various professional backgrounds, allowing them to work synergistically and to fulfill a goal of state universities to form mutually-beneficial partnerships with state government.

With regard to cost-effectiveness, this demonstration program utilizes federal funding, and it initially proposed a competent experimental design to evaluate the results of the training intervention. Moreover, it allows for the incorporation of the preferences of the employees in the choices of subsequent topics of training, instead of solely "imposing them from above."

There are also limitations. The economic pressures and turbulence in the mental 
health sector, and the closure of hospitals have significantly delayed and reduced the implementation of this project's design. Whereas originally 32 teams at a minimum of six hospitals and several community mental health centers were to be trained and evaluated within a three-year period, the final study will be limited to a maximum of only three hospitals and 15 teams. The employee turnover and layoffs have also impeded the follow-up of the original teams, and thus diminished the breadth and effectiveness of the evaluation of the training's impact. To date, one hospital has received two training sessions, (on standardized diagnosis and on team-building) with additional sessions reflecting their interests being scheduled. The other hospital's teams were given a "substitute" training session on "Maintaining Quality Care While Dealing with Change" a number of days before the entire hospital closed.

Thus, university researchers and collaborators must be prepared for changes "beyond their control" that occur in the larger political system in which public services are embedded. Indeed, not only are there continuing changes in the public mental health system that affect research design, data collection, and quality of results; but the rate of change appears to be accelerating, as reflected in the growing number of institutions actually closed or scheduled for closure, and the continuing reorganization of the workforce and the system and locus of service delivery.
Thus, researchers must be cautious regarding the ability of state departments and facilities to commit to multi-year programs, given the political environment in which they exist. Indeed, in these times, both researchers and agencies might be best served with carefully crafted, shorter-term workforce intervention projects. Such projects have less chance for disruption, yet can be significant enough to obtain the participation of both administration and staff.

Nevertheless, some benefits have accrued as a result of this project: some well-received training has already had some positive impact on the morale and effectiveness of some team members; new training materials on cultural sensitivity are being developed for dissemination throughout the department; and the budding collaborative relationship between the public mental health departments and several state universities has continued to grow and find new opportunities for future endeavors.

\section{REFERENCES}

Davis, M., \& Sanchez, A. M. (Eds.). (1989). Interdisciplinary collaboration between state mental health and higher education. Boulder, CO: Western Interstate Commission on Higher Education.

Talbott, J. A., \& Rabinowitz, C. B. (Eds.). (1986). Working together: State-university collaboration in mental health. Washington, DC: American Psychiatric Association Press. 